\title{
American Public Health Association
}

National Cancer Institute

\section{Source}

National Cancer Institute. American Public Health Association. NCI Thesaurus. Code C39318.

The oldest and largest organization of public health professionals in the world, representing more than 50,000 members from more than 50 occupations of public health. APHA brings together researchers, health service providers, administrators, teachers, and other health workers, forming multi-disciplinary environment for professional exchange, study, and action. Publishes the American Journal of Public Health. 